\title{
POSITIVE SOLUTIONS FOR A SYSTEM OF SINGULAR SECOND-ORDER INTEGRAL BOUNDARY VALUE PROBLEMS
}

\author{
JOHNNY HENDERSON* AND RODICA LUCA** \\ * Baylor University, Department of Mathematics \\ Waco, Texas, 76798-7328 USA \\ E-mail: Johnny_Henderson@baylor.edu \\ **Gh. Asachi Technical University, Department of Mathematics \\ Iaşi 700506, Romania \\ E-mail: rluca@math.tuiasi.ro
}

\begin{abstract}
We investigate the existence of positive solutions of a system of second-order nonlinear differential equations subject to integral boundary conditions, where the nonlinearities do not possess any sublinear or superlinear growth conditions and may be singular.

Key Words and Phrases: System of second-order differential equations, integral boundary conditions, positive solutions, singular functions, fixed point index.

2010 Mathematics Subject Classification: 34B10, 34B18, 47H10.

Acknowledgement. The authors thank the referee for his/her valuable comments and suggestions. The work of R. Luca was supported by a grant of the Romanian National Authority for Scientific Research, CNCS-UEFISCDI, project number PNII-ID-PCE-2011-3-0557.
\end{abstract}

\section{REFERENCES}

[1] B. Ahmad, A. Alsaedi, B.S. Alghamdi, Analytic approximation of solutions of the forced Duffing equation with integral boundary conditions, Nonlinear Anal., Real World Appl., 9(2008), 17271740 .

[2] F.M. Atici, G.Sh. Guseinov, On Green's functions and positive solutions for boundary value problems on time scales, J. Comput. Appl. Math., 141(2002), 75-99.

[3] A. Boucherif, Second-order boundary value problems with integral boundary conditions, Nonlinear Anal., 70(2009), 364-371.

[4] A. Boucherif, J. Henderson, Positive solutions of second order boundary value problems with changing signs Caratheodory nonlinearites, Electron. J. Qual. Theory Differ. Equ., 7(2006), $1-14$.

[5] N.P. Cac, A.M. Fink, J.A. Gatica, Nonnegative solutions of quasilinear elliptic boundary value problems with nonnegative coefficients, J. Math. Anal. Appl., 206(1997), 1-9.

[6] J.R. Cannon, The solution of the heat equation subject to the specification of energy, Quart. Appl. Math., 22(1964), 155-160.

[7] R. Yu. Chegis, Numerical solution of the heat conduction problem with an integral condition, Litov. Mat. Sb., 24(1984), 209-215. 
[8] Y. Cui, J. Sun, On existence of positive solutions of coupled integral boundary value problems for a nonlinear singular superlinear differential system, Electron. J. Qual. Theory Differ. Eq., 41(2012), 1-13.

[9] D.G. de Figueiredo, P.L. Lions, R.D. Nussbaum, A priori estimates and existence of positive solutions of semilinear elliptic equations, J. Math. Pures Appl., 61(1982), 41-63.

[10] C.S. Goodrich, Nonlocal systems of BVPs with asymptotically superlinear boundary conditions, Comment. Math. Univ. Carolin., 53(2012), 79-97.

[11] D. Guo, V. Lakshmikantham, Nonlinear Problems in Abstract Cones, Academic Press NY 1988.

[12] D.J. Guo, V. Lakshmikantham, Multiple solutions of two-point boundary value value problems of ordinary differential equations in Banach spaces, J. Math. Anal. Appl., 129(1988), 211-222.

[13] X. Hao, L. Liu, Y. Wu, Positive solutions for second order differential systems with nonlocal conditions, Fixed Point Theory, 13(2012), 507-516.

[14] J. Henderson, R. Luca, Positive solutions for singular systems of multi-point boundary value problems, Math. Methods Appl. Sci., 36(2013), 814-828.

[15] J. Henderson, R. Luca, Positive solutions for systems of second-order integral boundary value problems, Electron. J. Qual. Theory Differ. Eq., 70(2013), 1-21.

[16] J. Henderson, R. Luca, Existence and multiplicity of positive solutions for a system of higherorder multi-point boundary value problems, Adv. Dyn. Syst. Appl., 8(2013), no. 2, 233-245.

[17] J. Henderson, R. Luca, Positive solutions for singular systems of higher-order multi-point boundary value problems, Math. Model. Anal., 18(2013), no. 3, 309-324.

[18] J. Henderson, R. Luca, Positive solutions for systems of multi-point nonlinear boundary value problems, Comm. Appl. Nonlinear Anal., 21(2014), no. 3, 1-12.

[19] J. Henderson, R. Luca, Existence of positive solutions for a system of nonlinear second-order integral boundary value problems, Discrete Contin. Dyn. Syst., Suppl. 2015, Dyn. Sys. Differ. Equ. Appl., AIMS Proceedings, 596-604.

[20] J. Henderson, R. Luca, Boundary Value Problems for Systems of Differential, Difference and Fractional Equations. Positive Solutions, Elsevier, Amsterdam, 2016.

[21] G. Infante, F.M. Minhos, P. Pietramala, Non-negative solutions of systems of ODEs with coupled boundary conditions, Commun. Nonlinear Sci. Numer. Simul., 17(2012), 4952-4960.

[22] G. Infante, P. Pietramala, Existence and multiplicity of non-negative solutions for systems of perturbed Hammerstein integral equations, Nonlinear Anal., 71(2009), 1301-1310.

[23] N.I. Ionkin, Solution of a boundary-value problem in heat conduction with a nonclassical boundary condition, Differ. Eq., 13(1977), 204-211.

[24] T. Jankowski, Positive solutions to second-order differential equations with dependence on the first-order derivative and nonlocal boundary conditions, Boundary Value Probl., 8(2013), 1-20.

[25] M. Jia, P. Wang, Multiple positive solutions for integro-differential equations with integral boundary conditions and sign changing nonlinearities, Electron. J. Differ. Eq., 31(2012), 1-13.

[26] D.D. Joseph, E.M. Sparrow, Nonlinear diffusion induced by nonlinear sources, Quart. Appl. Math., 28(1970), 327-342.

[27] P. Kang, Z. Wei, Three positive solutions of singular nonlocal boundary value problems for systems of nonlinear second-order ordinary differential equations, Nonlinear Anal., 70(2009), 444-451.

[28] G.L. Karakostas, P.Ch. Tsamatos, Multiple positive solutions of some Fredholm integral equations arisen from nonlocal boundary-value problems, Electron. J. Differ. Eq., 30(2002), 1-17.

[29] H.B. Keller, D.S. Cohen, Some positone problems suggested by nonlinear heat generation, J. Math. Mech., 16(1967), 1361-1376.

[30] K.Q. Lan, Positive solutions of systems of Hammerstein integral equations, Commun. Appl. Anal., 15(2011), 521-528.

[31] B. Liu, L. Liu, Y. Wu, Positive solutions for singular systems of three-point boundary value problems, Comput. Math. Appl., 53(2007), 1429-1438.

[32] R. Luca, A. Tudorache, Existence of positive solutions to a system of higher-order semipositone integral boundary value problems, Comm. Appl. Anal., 19(2015), 589-604.

[33] R. Ma, Y. An, Global structure of positive solutions for nonlocal boundary value problems involving integral conditions, Nonlinear Anal., 71(2009), 4364-4376. 
[34] R. Ma, B. Thompson, Positive solutions for nonlinear m-point eigenvalue problems, J. Math. Anal. Appl., 297(2004), 24-37.

[35] A.A. Samarskii, Some problems of the theory of differential equations, Differ. Urav., 16(1980), 1925-1935.

[36] W. Song, W. Gao, Positive solutions for a second-order system with integral boundary conditions, Electron. J. Differ. Eq., 13(2011), 1-9.

[37] H. Su, Z. Wei, X. Zhang, J. Liu, Positive solutions of $n$-order and $m$-order multi-point singular boundary value system, Appl. Math. Comput., 188(2007), 1234-1243.

[38] J.R.L. Webb, G. Infante, Positive solutions of nonlocal boundary value problems involving integral conditions, Nonlinear Differ. Eq. Appl., 15(2008), 45-67.

[39] Z. Yang, Positive solutions to a system of second-order nonlocal boundary value problems, Nonlinear Anal., 62(2005), 1251-1265.

[40] Z. Yang, Positive solutions of a second-order integral boundary value problem, J. Math. Anal. Appl., 321(2006), 751-765.

[41] Z. Yang, D. O'Regan, Positive solvability of systems of nonlinear Hammerstein integral equations, J. Math. Anal. Appl., 311(2005), 600-614.

[42] Z. Yang, Z. Zhang, Positive solutions for a system of nonlinear singular Hammerstein integral equations via nonnegative matrices and applications, Positivity, 16(2012), 783-800.

Received: October 8, 2015; Accepted: June 28, 2016. 